\title{
Disparities in mammographic screening for Asian women in California: a cross-sectional analysis to identify meaningful groups for targeted intervention Scarlett Lin Gomez ${ }^{* 1,2}$, Susanna Tan ${ }^{3}$, Theresa HM Keegan ${ }^{1,2}$ and Christina A Clarke ${ }^{1,2}$
}

Address: ${ }^{1}$ Northern California Cancer Center, 2201 Walnut Ave, Suite 300, Fremont, CA, 94538, USA, ${ }^{2}$ Department of Health Research and Policy, Stanford University School of Medicine, Stanford, CA, USA and ${ }^{3}$ Northwestern Feinberg School of Medicine, Northwestern University, Chicago, IL, 94305, USA

Email: Scarlett Lin Gomez* - scarlett@nccc.org; Susanna Tan - s-tan@md.northwestern.edu; Theresa HM Keegan - tkeegan@nccc.org; Christina A Clarke - tina@nccc.org

* Corresponding author

Published: 26 October 2007

BMC Cancer 2007, 7:20I doi:10.1 I86/147|-2407-7-20I
Received: 30 March 2007

Accepted: 26 October 2007

This article is available from: http://www.biomedcentral.com/I47I-2407/7/20I

(c) 2007 Gomez et al; licensee BioMed Central Ltd.

This is an Open Access article distributed under the terms of the Creative Commons Attribution License (http://creativecommons.org/licenses/by/2.0), which permits unrestricted use, distribution, and reproduction in any medium, provided the original work is properly cited.

\begin{abstract}
Background: Breast cancer is the most commonly diagnosed cancer among the rapidly growing population of Asian Americans; it is also the most common cause of cancer mortality among Filipinas. Asian women continue to have lower rates of mammographic screening than women of most other racial/ethnic groups. While prior studies have described the effects of sociodemographic and other characteristics of women on non-adherence to screening guidelines, they have not identified the distinct segments of the population who remain at highest risk of not being screened.

Methods: To better describe characteristics of Asian women associated with not having a mammogram in the last two years, we applied recursive partitioning to population-based data $(N=152 I)$ from the 200I California Health Interview Survey (CHIS), for seven racial/ethnic groups of interest: Chinese, Japanese, Filipino, Korean, South Asian, Vietnamese, and all Asians combined.

Results: We identified two major subgroups of Asian women who reported not having a mammogram in the past two years and therefore, did not follow mammography screening recommendations: I) women who have never had a pap exam to screen for cervical cancer (68\% had no mammogram), and 2) women who have had a pap exam, but have no women's health issues (osteoporosis, using menopausal hormone therapies, and/or hysterectomy) nor a usual source of care (62\% had no mammogram). Only 19\% of Asian women who have had pap screening and have women's health issues did not have a mammogram in the past two years. In virtually all ethnic subgroups, having had pap or colorectal screening were the strongest delineators of mammography usage. Other characteristics of women least likely to have had a mammogram included: Chinese non-U.S. citizens or citizens without usual source of health care, Filipinas with no health insurance, Koreans without women's health issues and public or no health insurance, South Asians less than age 50 who were unemployed or non-citizens, and Vietnamese women who were never married.

Conclusion: We identified distinct subgroups of Asian women at highest risk of not adhering to mammography screening guidelines; these data can inform outreach efforts aimed at reducing the disparity in mammography screening among Asian women.
\end{abstract}




\section{Background}

Asians and Pacific Islanders are among the most rapidly growing racial/ethnic population groups in the United States (U.S.), with most of the growth attributable to high immigration rates from Asian and Pacific Island countries $[1,2]$. California is one of the main geographic targets of this immigration, such that more than one-third of all U.S. Asians and Pacific Islanders (API), or four million people, now live in California [3-7]. Growth in API groups is expected to continue over time, with a projected population of 11 million California APIs by 2025 [7].

Breast cancer consistently is the most commonly diagnosed cancer and the second most common cause of cancer mortality among U.S. Asians; among Filipinas, it is the most common cause of cancer mortality [8,9]. Despite overwhelming clinical evidence supporting the efficacy of mammograms for reducing breast cancer mortality [10] and the Healthy People 2010 objective to have $70 \%$ of U.S. women age 40 and older receive a mammogram at least once every two years, recent population risk factor surveys have shown that use of mammography continues to vary by racial/ethnic group [11-13]. According to the 2001 California Health Interview Survey (CHIS), Whites, African Americans, and Latinas have already met the national objective of having a mammogram in the past two years $(78.1 \%, 78.5 \%$, and $69.9 \%$, respectively) but Asians $(67.2 \%)$ and Native Hawaiians/other Pacific Islanders (63.4\%) lag behind [13]. Like other women, Asian Americans may not follow mammography screening guidelines because of practical considerations such as lack of time, money, health insurance, transportation, or having a usual source of care [14-25]; lack of encouragement by physicians or family $[14,16,22,24-27]$; and perceptions that mammograms are inconvenient, uncomfortable, or dangerous; or perceptions that breast cancer is not a serious illness $[24,26,28]$. However, sociocultural factors more relevant to immigrant groups especially those recently immigrated to the U.S., like low level of education $[18,26]$, inability to speak English $[19,25,29,30]$, low level of acculturation $[17,18,22,24,26,27,31]$, and racial/ethnic or cultural discordance with providers $[17,32]$, are also associated with low mammography utilization.

While prior studies have been able to identify characteristics associated independently with use of mammography screening, most of these studies have been conducted with convenience-based, rather than population-based, representative samples of women. Moreover, relying on standard regression techniques, nearly all previous studies have identified independent effects of socioeconomic and other characteristics associated with mammography use. With these traditional techniques, it is more difficult to consider the complex interactions among multiple factors for describing important high risk groups most likely not to comply with mammography screening recommendations [33]. Public health interventions would be most effective and cost efficient if applied to segments of the population most at risk. Thus, in this analysis, we applied the novel statistical method recursive partitioning (RP) to a large, population-based resource to identify clustered characteristics of Asian American women most likely not to follow mammography screening guidelines and who might benefit from targeted intervention. We conducted analyses separately for Asians as a group as well as for ethnic subgroups, because of demonstrated heterogeneity across these subgroups in screening rates $[34,35]$ and the proportion of early stage diagnoses $(51 \%, 41 \%$, and $35 \%$ stage I breast cancer among Japanese, Chinese, and Filipinas, respectively [36]).

\section{Methods \\ CHIS data and study sample}

We used population-based data from the 2001 CHIS, a telephone survey based on a geographically stratified sample, identified through random-digit-dialing (RDD) that over-sampled under-represented geographic areas and ethnic groups. The data collected by CHIS, the largest state health survey, are intended to provide health planners, policy makers, county governments, advocacy groups, and communities a detailed picture of the health and health care needs among California's diverse population [37]. The CHIS sample represents the geographic and racial/ethnic diversity of California; interviews are conducted in multiple languages to accommodate the state's rich racial/ethnic diversity. CHIS 2001 collected information from more than 55,000 households across California and conducted interviews in seven languages: English, Spanish, Mandarin, Cantonese, Vietnamese, Korean, and Cambodian. Among the households who completed a screening interview (59.2\% of RDD sample), the response rate for the adult interview across the state was $63.7 \%$ [38] for an overall response rate of $37.7 \%$, which was comparable to response rates among Asians: South Asian $(39.5 \%)$, Japanese $(35.3 \%)$, Korean $(42.5 \%)$, and Vietnamese (35.3\%); response rates for Chinese and Filipino were not available from CHIS as they were included in the larger RDD samples and not in the ethnicity-specific oversampling efforts [39].

This analysis included women of self-reported (or CHISimputed) Asian ethnicities who at the time of interview, did not report a prior history of breast cancer and who were aged 41 years or older. This age cut-off for sample selection was chosen because of screening guidelines recommending annual mammograms starting at age 40 [40]. Those with prior history of breast cancer were excluded $(\mathrm{N}$ $=39$ women who reported a prior diagnosis of breast cancer, and $\mathrm{N}=5$ women for whom this status was not ascer- 
tained) because their screening habits are likely influenced by their prior diagnoses and routine medical surveillance. We excluded 22 women for whom mammography status was not ascertained. Thus, our final analytic sample $(\mathrm{N}=1521)$ included women with the following ethnic identifications: Chinese $(n=382)$, Japanese $(\mathrm{n}=275)$, Filipino $(\mathrm{n}=269)$, Korean $(\mathrm{n}=244)$, South Asian $(n=125)$, and Vietnamese $(n=226)$. The South Asian subgroup includes women of self-reported descent from South Asian countries such as India, and Pakistan.

\section{Outcome and explanatory variables for recursive partitioning}

RP $[41,42]$ was used to identify mutually exclusive subgroups, with variations in outcome, delineated by combinations of explanatory characteristics. The dichotomous outcome variable represented categorization of responses to the question "How long ago did you have your most recent mammogram?". We selected a cut-off of two years in reference to the Healthy People 2010 goal of having $70 \%$ of women in the United States receive a mammogram within the past two years [43]. In addition, women were considered to have received a screening mammogram within the past two years if it was conducted "as part of a routine physical exam or screening"; other reasons (7\% of respondents), including "because of a specific breast problem", "as a follow-up to a previously identified breast problem", and "as a result of a baseline or initial mammogram" were considered mammograms that were conducted for diagnostic purposes.

The 25 explanatory variables submitted into the RP procedure are presented in Table 1 . These variables were selected from among the CHIS questions because they have previously been shown or were hypothesized to be associated with mammography screening. Two of us (SLG \& ST) independently reviewed the CHIS variables and selected those to be included in the RP analysis; discrepancies were resolved by discussion. Prior to RP analysis, several variables were modified from their original CHIS format, including income, which was adjusted for household size, and percentage of lifetime in the U.S., which was derived by dividing the number of years lived in the U.S. by age in years. Categories of English-speaking proficiency (speaks English only, very well, well, or not well) and education were grouped (Table 1) according to the distributions for each subgroup to overcome sparse numbers in the sub-categories. We also included a variable designating eligibility for public programs, including public housing subsidies, general assistance and relief, food stamps, disability, or Women, Infants, and Children (WIC). We included two variables characterizing preexisting health conditions: 1) having had pre-existing health issues, which included self-report of at least one of the following: arthritis, asthma, diabetes, or high blood pressure; 2) having women's health issues, which included at least one of the following: taking hormone supplements, history of osteoporosis, or hysterectomy. We created a variable indicating ever having had a Pap exam to screen for cervical cancer based on the question "Have you ever had a Pap smear test to check for cervical cancer." We created another variable indicating ever having been screened for colorectal cancer based on the questions "Have you ever had a Sigmoidoscopy, Colonoscopy, or a Proctoscopy to look for signs of cancer or other problems in your colon" and "Have you ever done a blood stool test, using a home test kit?"; women were considered to have ever been screened for colorectal cancer if their most recent colorectal exam was conducted "as part of a routine physical exam or screening test"; other reasons including "because of a specific problem" or "as a followup to an earlier test or screening exam" were considered procedures done for diagnostic purposes. We also combined the Pap and colorectal cancer screening variables into one variable indicating ever use of other cancer screening tests. For all of the explanatory variables, "refused", "don't know", or "not ascertained" responses to survey questions were coded as missing in the analysis.

\section{Statistical analysis \& recursive partitioning}

We used RP, a non-parametric method that produces a classification tree in which subjects are assigned to mutually exclusive subsets according to a set of explanatory variables. Unlike traditional regression methods, highly correlated variables can be entered simultaneously because RP manages variables individually. The first step in RP involves examining each explanatory variable and selecting one binary split across the sample on one explanatory variable that minimizes the within-group variance in the outcome variable in the two resultant nodes. This process is repeated for subsequent explanatory variables until further partitioning is not possible; however, the final tree, with small numbers of subjects in the terminal nodes (minimum of 5, per our stopping rule), is subject to high misclassification errors. Therefore, the next step involves "pruning" the tree by sequentially cutting away terminal nodes. The optimal tree, selected via crossvalidation (ten-fold in our analysis), has the most splits but the lowest misclassification rate [44]. Additional details about RP are available elsewhere [42,44-46]. RP analyses were conducted using the RPART routine in the $R$ statistical software program [45]. For the variables English proficiency and education, for which two versions of each variable are created depending on the Asian subgroup, the values are set to "missing" for individuals for whom the variable does not apply. For example, for the variable education (among only Vietnamese), this variable is set to missing for women who are not Vietnamese. One of the most powerful advantages of the RPART procedure is its 
Table I: Distribution of Asian women according to mammogram (mam) status, by selected characteristics 1

\begin{tabular}{|c|c|c|c|}
\hline Characteristic & $\begin{array}{l}N(\text { row } \%) \text { Mam in } \\
\text { past } 2 \text { yrs, } N=981\end{array}$ & $\begin{array}{l}N(\text { row } \%) \text { No mam in } \\
\text { past } 2 \text { yrs, } N=540\end{array}$ & $\begin{array}{l}\text { Total } \\
(N=1521)\end{array}$ \\
\hline \multicolumn{4}{|l|}{ Asian subgroup } \\
\hline Chinese & $246(64)$ & $136(36)$ & 382 \\
\hline Japanese & $194(71)$ & $81(29)$ & 275 \\
\hline Filipina & $178(66)$ & $91(34)$ & 269 \\
\hline Korean & $127(52)$ & 117 (48) & 244 \\
\hline South Asian & $79(63)$ & $46(37)$ & 125 \\
\hline \multirow[t]{2}{*}{ Vietnamese } & $157(69)$ & $69(31)$ & 226 \\
\hline & \multicolumn{2}{|c|}{$\mathrm{p}$-value ${ }^{2}=<.0001$} & \\
\hline \multicolumn{4}{|l|}{ Age at interview } \\
\hline $41-49$ & $353(59)$ & $248(4 I)$ & 601 \\
\hline $50-64$ & $391(70)$ & $164(30)$ & 555 \\
\hline \multirow[t]{2}{*}{$65+$} & $237(65)$ & $128(35)$ & 365 \\
\hline & \multicolumn{2}{|c|}{$\mathrm{p}$-value $=.0002$} & \\
\hline English speaking proficiency (Chinese, Korean, Vietnamese) & 530 & 322 & \\
\hline English not well & $294(59)$ & $204(4 I)$ & 498 \\
\hline \multirow[t]{2}{*}{ English well, very well, only } & $236(67)$ & $118(33)$ & 354 \\
\hline & \multicolumn{2}{|c|}{$\mathrm{p}$-value $=.024$} & \\
\hline English speaking proficiency (Filipino, Japanese, South Asian) & 451 & 218 & \\
\hline English well, not well & $146(65)$ & $77(35)$ & 223 \\
\hline \multirow[t]{2}{*}{ English very well, only } & $305(68)$ & $|4|(32)$ & 446 \\
\hline & \multicolumn{2}{|c|}{$\mathrm{p}$-value $=.448$} & \\
\hline Education (excluding Vietnamese) & 824 & 471 & \\
\hline High school diploma or less & $248(62)$ & $155(38)$ & 403 \\
\hline Some college, vocational school & $187(63)$ & $109(37)$ & 296 \\
\hline \multirow[t]{2}{*}{ Bachelor's degree or more } & \multirow{2}{*}{\multicolumn{2}{|c|}{$p$-value $=.477207(35)$}} & 596 \\
\hline & & & \\
\hline Education (only Vietnamese) & 157 & 69 & \\
\hline High school diploma or less & $123(69)$ & $56(31)$ & 179 \\
\hline \multirow{2}{*}{ Some college or more } & $34(72)$ & $13(28)$ & 47 \\
\hline & \multicolumn{2}{|c|}{$\mathrm{D}$-value $=.631$} & \\
\hline \multicolumn{4}{|l|}{ Annual household income adjusted for household size } \\
\hline$<\$ 10,000$ (per household member) & $186(60)$ & $123(40)$ & 309 \\
\hline$\$ 10,000-\$ 19,999$ & $269(61)$ & $173(39)$ & 442 \\
\hline$\$ 20,000-\$ 33,749$ & $261(69)$ & $118(31)$ & 379 \\
\hline \multirow[t]{2}{*}{$\$ 33,750+$} & $265(68)$ & $136(32)$ & 391 \\
\hline & \multicolumn{2}{|c|}{$\mathrm{D}$-value $=.018$} & \\
\hline Employer type & 968 & 531 & \\
\hline Unemployed & $458(66)$ & $24 I(34)$ & 699 \\
\hline Private & $325(63)$ & $190(37)$ & 515 \\
\hline Federal, state, local & $114(7 \mid)$ & $47(29)$ & 161 \\
\hline Self-employed, family business & $71(57)$ & $53(43)$ & 124 \\
\hline & $\mathrm{p}-\mathrm{v}$ & $=.094$ & \\
\hline Employment hours (per week) & & & \\
\hline Unemployed & $458(65)$ & $243(35)$ & 701 \\
\hline $1-30$ hours & $112(62)$ & $69(38)$ & $|8|$ \\
\hline$>30$ hours & $411(64)$ & $228(36)$ & 639 \\
\hline & $\mathrm{p}-\mathrm{v}$ & $=.682$ & \\
\hline Health insurance & & & \\
\hline No & $76(44)$ & $97(56)$ & 173 \\
\hline Yes & $905(67)$ & $443(33)$ & 1348 \\
\hline & p-val & $=<.0001$ & \\
\hline Type of health insurance (among insured) & 905 & 443 & \\
\hline $\begin{array}{l}\text { Public (Medicaid only, Medicare only, Medicare \& Medicaid, other } \\
\text { public) }\end{array}$ & $192(60)$ & $127(40)$ & 319 \\
\hline Private (employment-based, private, Medicare \& private) & $713(69)$ & $316(3 \mid)$ & 1029 \\
\hline & $\mathrm{p}-\mathrm{v}$ & $=.003$ & \\
\hline Managed care health plan (among insured) & 877 & 427 & \\
\hline No & $291(65)$ & $160(35)$ & 451 \\
\hline Yes & $586(69)$ & $267(31)$ & 853 \\
\hline & & $=.127$ & \\
\hline
\end{tabular}


Table I: Distribution of Asian women according to mammogram (mam) status, by selected characteristics ${ }^{\text {(Continued) }}$

\begin{tabular}{|c|c|c|c|}
\hline \multicolumn{4}{|c|}{$\begin{array}{l}\text { Public program eligibility (public housing subsidies, general assistance and } \\
\text { relief, food stamps, disability, WIC) }\end{array}$} \\
\hline No & $841(65)$ & $456(35)$ & 1297 \\
\hline \multirow[t]{2}{*}{ Yes } & $140(63)$ & $84(37)$ & 224 \\
\hline & \multicolumn{2}{|c|}{$\mathrm{P}$-value $=.499$} & \\
\hline Marital status & 979 & 540 & \\
\hline Married & $620(65)$ & $331(35)$ & 951 \\
\hline Widowed, divorced, separate, living with partner & $290(64)$ & $160(36)$ & 450 \\
\hline \multirow[t]{2}{*}{ Never married } & $69(58)$ & $49(42)$ & 118 \\
\hline & \multicolumn{2}{|c|}{$\mathrm{p}$-value $=.355$} & \\
\hline \multicolumn{4}{|l|}{ Percent of lifetime lived in U.S. } \\
\hline$<10 \%$ of life in U.S. & $32(40)$ & $49(60)$ & 81 \\
\hline $10-25 \%$ of life in U.S. & $138(61)$ & $89(39)$ & 227 \\
\hline$>25 \%$ of life in U.S. & $580(65)$ & $309(35)$ & 889 \\
\hline \multirow[t]{2}{*}{ U.S. born } & $231(7 I)$ & $93(29)$ & 324 \\
\hline & \multicolumn{2}{|c|}{$\mathrm{p}$-value $<.0001$} & \\
\hline \multicolumn{4}{|l|}{ Citizenship status } \\
\hline U.S. born & $23 I(7 I)$ & $93(29)$ & 324 \\
\hline Naturalized citizen & $600(68)$ & $283(32)$ & 883 \\
\hline \multirow[t]{2}{*}{ Non-citizen } & $150(48)$ & $164(52)$ & 314 \\
\hline & \multicolumn{2}{|c|}{$\mathrm{p}$-value $<.0001$} & \\
\hline Usual source of care & 980 & 539 & \\
\hline No & $56(38)$ & $90(62)$ & 146 \\
\hline \multirow[t]{2}{*}{ Yes } & $924(67)$ & $449(33)$ & 1373 \\
\hline & \multicolumn{2}{|c|}{$\mathrm{p}$-value $<.0001$} & \\
\hline \multicolumn{4}{|l|}{ Went to another country for care } \\
\hline No & $959(65)$ & $526(35)$ & 1485 \\
\hline \multirow[t]{2}{*}{ Yes } & $22(6 \mathrm{I})$ & $14(39)$ & 36 \\
\hline & \multicolumn{2}{|c|}{$\mathrm{p}$-value $=.667$} & \\
\hline Personal history of (non-breast) cancer & 979 & 539 & \\
\hline No & $944(64)$ & $524(36)$ & 1468 \\
\hline \multirow[t]{2}{*}{ Yes } & $35(70)$ & $15(30)$ & 50 \\
\hline & & & \\
\hline Blood relative with cancer & 974 & 535 & \\
\hline No & $633(62)$ & $380(38)$ & 1013 \\
\hline Yes & 341 (69) & $155(3 \mid)$ & 496 \\
\hline & & & \\
\hline Blood relative with breast cancer & & & \\
\hline No & $943(64)$ & $526(36)$ & 1469 \\
\hline Yes & $38(73)$ & $14(27)$ & 52 \\
\hline & & & \\
\hline $\begin{array}{l}\text { Pre-existing health condition (arthritis, asthma, diabe } \\
\text { pressure) }\end{array}$ & & & \\
\hline No & $466(62)$ & $287(38)$ & 753 \\
\hline Yes & $515(67)$ & $253(33)$ & 768 \\
\hline & & & \\
\hline Use of other screenings (pap exam and/or colon-rec & & & \\
\hline No & $46(29)$ & $113(7 I)$ & 159 \\
\hline Yes & $935(69)$ & $427(31)$ & 1362 \\
\hline & & & \\
\hline Ever had pap smear to check for cervical cancer & & & \\
\hline No & $62(32)$ & $13 \mid(68)$ & 193 \\
\hline Yes & $919(69)$ & $409(31)$ & 1328 \\
\hline & & & \\
\hline Ever had colon-rectal screening exam & & & \\
\hline No & $589(58)$ & $432(42)$ & 1021 \\
\hline Yes & $392(78)$ & $108(22)$ & 500 \\
\hline & & & \\
\hline $\begin{array}{l}\text { Has women's health issues (has osteoporosis, takes } \mathrm{h} \\
\text { to control menopause, had hysterectomy) }\end{array}$ & & & \\
\hline No & $568(57)$ & $426(43)$ & 994 \\
\hline Yes & $413(78)$ & 114 (22) & 527 \\
\hline & & & \\
\hline
\end{tabular}

I Distribution* of Asian women according to mammogram status (mammogram within the past two years), by selected characteristics, $\mathrm{CHIS} 200 \mathrm{I}$ $(N=152 I)$; relative distributions are not adjusted for CHIS sampling weights.

$2 \mathrm{p}$-value for chi-square test comparing the distribution among non-users to users. 
ability to retain observations with partially missing data [45]. Probabilities (and corresponding 95\% confidence intervals) of not having had a mammogram in the past two years are computed for each tree terminal node (represented by rectangles); testing for statistically significant differences in these probabilities among groups was not conducted. In the RP analysis, screening for other cancers were the major and sometimes only identified delineator for most groups. In the case where screening for other cancers was the only identified delineator, a separate RP analysis was conducted excluding this variable in order to identify other salient characteristics influencing mammography screening that might better inform interventions.

\section{Human subjects protection}

Institutional review board (ethical) approval was not sought for this research as it was based on a de-identified, public-use dataset.

\section{Results}

Table 1 shows the numbers and relative distributions of the 1521 study subjects according to mammography use within the past two years, and sociodemographic factors. Overall, 540 (35.5\%) of all Asian women aged 41 or older reported not having a mammogram in the past two years. This proportion ranged from $29 \%$ among Japanese to $48 \%$ among Koreans and differed most notably by age at interview, presence of health insurance, percent of lifetime lived in the U.S., citizenship status, having a usual source of care, use of other cancer screening tests, and having women's health issues. Smaller differences in the proportion of mammogram users were also seen by English language proficiency (among Chinese, Koreans, and Vietnamese), income, type of health insurance, family history of cancer, and pre-existing health conditions.

RP results are presented graphically (Figures 1, 2, 3, 4, 5, $6,7)$ with probabilities of not having a mammogram for relevant subgroups detailed in Table 2. Among all Asian subgroups combined, the optimal RP tree was based on splits of three explanatory variables (Figure 1): 1) ever having a pap screening exam, 2) having other women's health issues, and 3 ) having a usual source of care. Having a pap exam was the strongest delineator. $68 \%$ of Asian women who had not received a pap exam also did not have a mammogram in the past two years (node 1 ). Another high-risk group (node 4 ) comprised $62 \%$ of women who did not have a mammogram; these were women who have had a pap exam, but have had no other women's health issues and no usual source of care.

In Chinese females (Figure 2), the strongest delineator of mammography screening was having ever had a colorectal screening exam. Among Chinese women who have had a

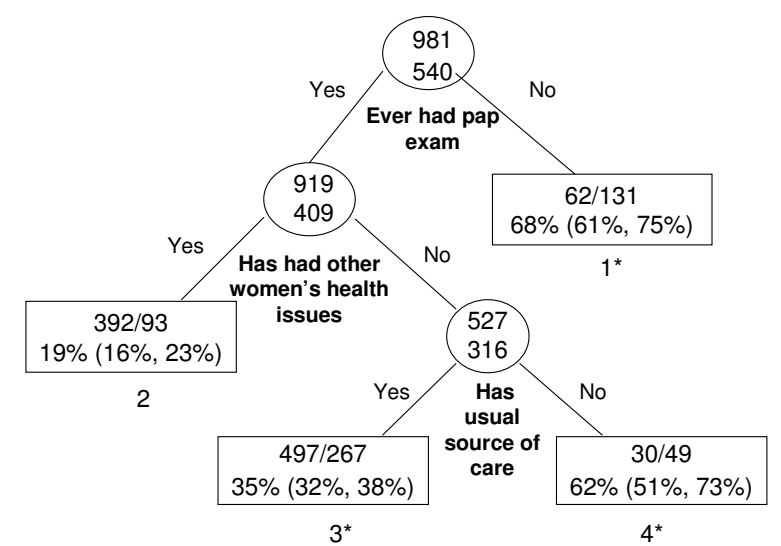

* Does not meet Healthy People 2010 goal

$\begin{gathered}487 / 234 \\ 32 \%(30 \%, 34 \%)\end{gathered}$
$2 \longleftarrow$ Probability of not having had mammogram $(95 \% \mathrm{Cl})$
Terminal node number

\section{Figure I}

Recursive partitioning classification tree for Asian females 4I years and older, CHIS 200I.

colorectal screening exam, $17 \%$ did not have a mammogram within the past two years (node 1), compared to $63 \%$ among women who did not have a colorectal exam and were non-U.S. citizens (node 2). Another high-risk group was Chinese women who did not have a colorectal exam, were U.S. citizens, and had no usual source of care (node 4).

Colorectal and pap screening exams were the only two delineating variables in Japanese females (Figure 3). The

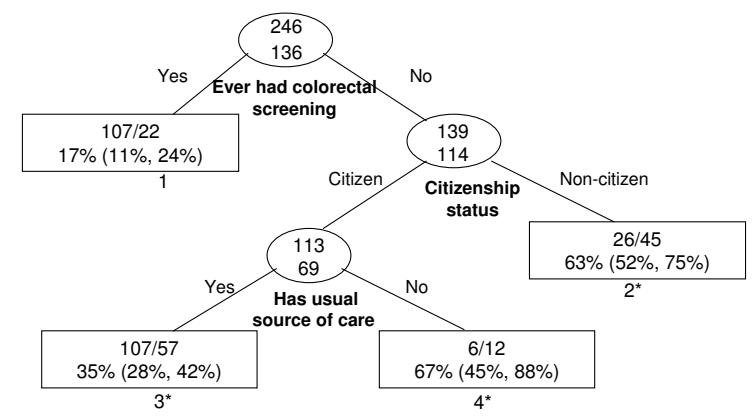

* Does not meet Healthy People 2010 goal

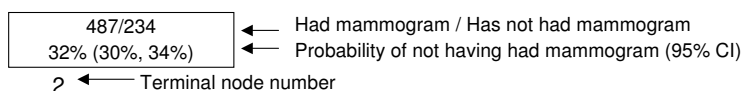

\section{Figure 2}

Recursive partitioning classification tree for Chinese females $4 \mathrm{I}$ years and older, CHIS $200 \mathrm{I}$. 


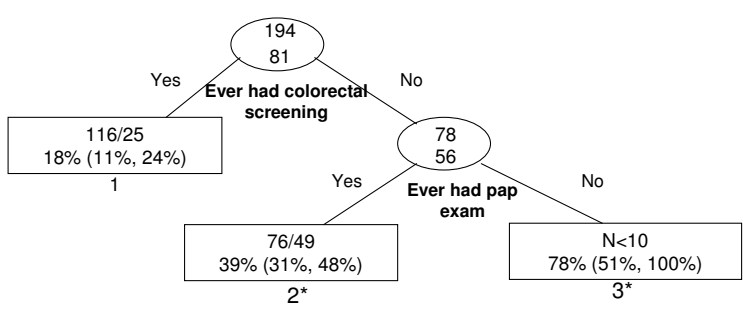

* Does not meet Healthy People 2010 goal

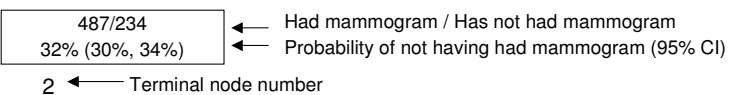

Figure 3

Recursive partitioning classification tree for Japanese females $4 \mathrm{I}$ years and older, including pap and colon screening variable, CHIS 200I.

lowest risk group was Japanese women who have ever been screened for colorectal cancer (node 1), and the highest risk group was Japanese women who have never been screened for colorectal or cervical cancer (node 3). Because screening for other cancers was selected as the only delineator of mammography screening, we conducted RP excluding the pap and colorectal cancer screening variables (data not shown). The lowest risk groups were Japanese women with women's health issues, and women with women's health issues, a usual source of care, and who were unemployed. The resultant high risk groups were based on small numbers of people.

The most discriminating explanatory variable for Filipinas (Figure 4) was ever having any pap or colorectal screening exam; $85 \%$ of women without either exam also did not have a mammogram within the past two years (node 1). Among women who have had at least one pap or colorectal exam, having health insurance was an important delin-

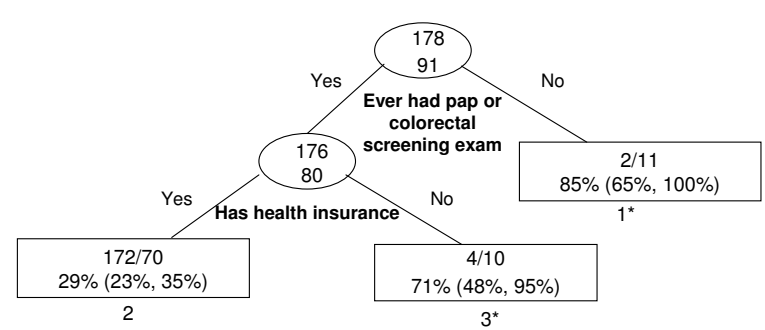

* Does not meet Healthy People 2010 goal

\begin{tabular}{|c|l}
\hline $487 / 234$ & Had mammogram / Has not had mammogram \\
$32 \%(30 \%, 34 \%)$ & Probability of not having had mammogram $(95 \% \mathrm{Cl})$ \\
\hline $2 \longleftarrow$ Terminal node number
\end{tabular}

\section{Figure 4}

Recursive partitioning classification tree for Filipina females $4 \mathrm{I}$ years and older, CHIS $200 \mathrm{I}$.

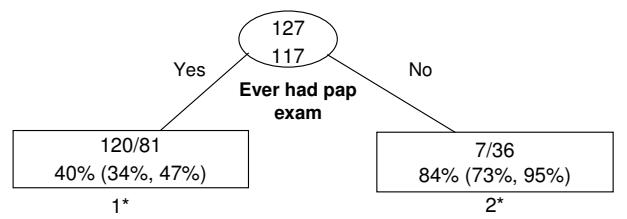

* Does not meet Healthy People 2010 goal

\begin{tabular}{|c|l}
\hline $487 / 234$ & Had mammogram / Has not had mammogram \\
$32 \%(30 \%, 34 \%)$ & Probability of not having had mammogram $(95 \% \mathrm{Cl})$ \\
\hline $2 \longleftarrow$ Terminal node number
\end{tabular}

\section{Figure 5}

Recursive partitioning classification tree for Korean females $4 \mathrm{I}$ years and older, including pap and colon screening variables, CHIS 200I.

eator, as $71 \%$ of those without health insurance did not have a mammogram (node 3 ).

Among Korean females (Figure 5), ever having a pap exam was the most important delineator of mammography use. Among Korean women who have never had a pap exam, $84 \%$ have not had a mammogram (node 2 ). When RP analysis excluded pap and colorectal cancer screening variables (data not shown), women's health issues and health insurance type were found to be additionally important delineators. The lowest risk group was Korean women who have other women's health issues, while the highest risk group was Korean women who did not have other women's health issues and had public or no health insurance.

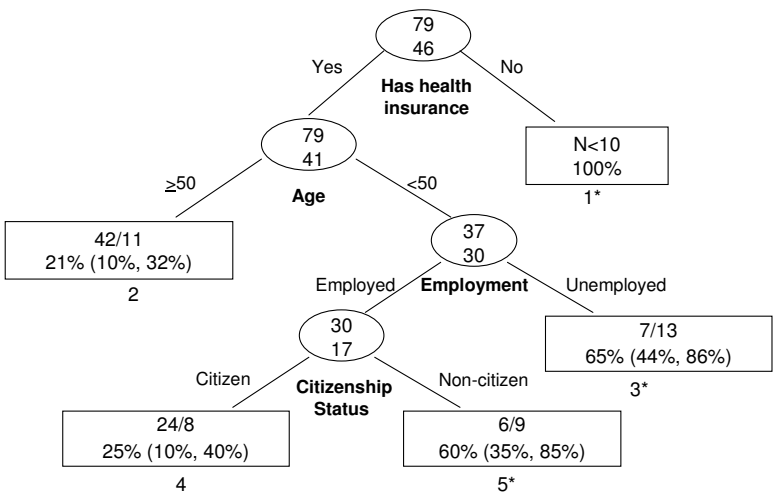

\begin{tabular}{l} 
* Does not meet Healthy People 2010 goal \\
$\begin{array}{c}487 / 234 \\
32 \%(30 \%, 34 \%)\end{array}$ Pad mammogram / Has not had mammogram \\
\hline $2 \longleftarrow$ Terminal node number
\end{tabular}

\section{Figure 6}

Recursive partitioning classification tree for South Asian females $4 \mathrm{I}$ years and older, CHIS $200 \mathrm{I}$. 


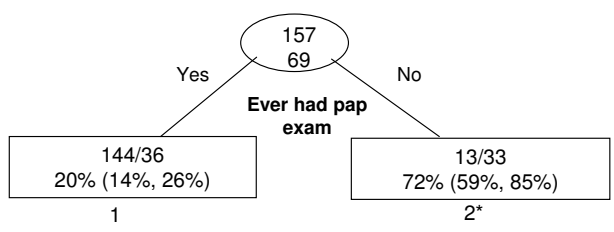

* Does not meet Healthy People 2010 goal

\begin{tabular}{|c|}
\hline $487 / 234$ \\
$32 \%(30 \%, 34 \%)$
\end{tabular} Probability of not having had mammogram $(95 \% \mathrm{Cl})$

\section{Figure 7}

Recursive partitioning classification tree for Vietnamese females $4 \mathrm{I}$ years and older, including pap and colon screening variables, CHIS $200 \mathrm{I}$.

Among South Asians (Figure 6), health insurance, age, employment, and citizenship status were identified as important delineating variables. The highest risk groups were nodes 1 (women with no health insurance), 3 (women with health insurance, younger than age 50, and were unemployed), and 5 (women with health insurance, younger than age 50 , were employed, and were non-citizens).

Among Vietnamese women (Figure 7), $72 \%$ of women without a pap exam did not had a mammogram in the previous two years (node 2); however, this was the only discriminating variable selected by RP. Excluding the pap and colorectal cancer screening variables (data not shown), marital status emerged as an additionally important predictor; among Vietnamese women who have never been married, $67 \%$ did not have a mammogram in the previous two years. Additional analyses showed that Vietnamese women who have never been married were significantly more likely than women who have been married to have had pap and/or colorectal screening, and were more likely (not significant) to be employed more than 30 hours per week and to receive public assistance.

Table 2: Probability of not having mammogram among risk groups identified from recursive partitioning

\begin{tabular}{|c|c|c|c|}
\hline Node & Risk group characteristics & $\mathbf{N}$ & $\begin{array}{l}\text { Probability of not having a mammogram } \\
\text { in the past two years }(95 \% \mathrm{Cl})\end{array}$ \\
\hline \multicolumn{4}{|c|}{ All Asians combined $(\mathrm{N}=1521)$} \\
\hline I & Never had pap exam & 193 & $68 \%(61 \%, 75 \%) *$ \\
\hline 2 & Ever had pap exam. Has women's health issue(s). & 485 & $19 \%(16 \%, 23 \%)$ \\
\hline 3 & Ever had pap exam. No women's health issues. Has usual source of care. & 764 & $35 \%(32 \%, 38 \%)^{*}$ \\
\hline 4 & Ever had pap exam. No women's health issues. No usual source of care. & 79 & $62 \%(51 \%, 73 \%)^{*}$ \\
\hline \multicolumn{4}{|c|}{ Chinese $(N=382)$} \\
\hline I & Ever had colorectal cancer screening. & 129 & $17 \%(11 \%, 24 \%)$ \\
\hline 2 & Never had colorectal cancer screening. Non U.S. citizen. & 71 & $63 \%(52 \%, 75 \%) *$ \\
\hline 3 & $\begin{array}{l}\text { Never had colorectal cancer screening. U.S. citizen. Has usual source of } \\
\text { care. }\end{array}$ & 164 & $35 \%(28 \%, 42 \%) *$ \\
\hline 4 & $\begin{array}{l}\text { Never had colorectal cancer screening. U.S. citizen. No usual source of } \\
\text { care. }\end{array}$ & 18 & $67 \%(45 \%, 88 \%)^{*}$ \\
\hline \multicolumn{4}{|c|}{ Japanese $(N=275)$} \\
\hline 1 & Ever had colorectal cancer screening. & 141 & $18 \%(11 \%, 24 \%)$ \\
\hline 2 & Never had colorectal cancer screening. Ever had pap exam. & 138 & $39 \%(31 \%, 48 \%)^{*}$ \\
\hline 3 & Never had colorectal cancer screening. Never had pap exam. & $<10$ & $78 \%(51 \%, 100 \%)^{*}$ \\
\hline \multicolumn{4}{|c|}{ Filipina $(N=269)$} \\
\hline 1 & Never had pap or colorectal cancer screening. & 13 & $75 \%(65 \%, 100 \%)^{*}$ \\
\hline 2 & Ever had pap or colorectal cancer screening. Has health insurance. & 242 & $29 \%(23 \%, 35 \%)$ \\
\hline 3 & Ever had pap or colorectal cancer screening. Has no health insurance. & 15 & $71 \%(48 \%, 95 \%)^{*}$ \\
\hline \multicolumn{4}{|c|}{ Korean $(N=244)$} \\
\hline I & Ever had pap exam. & 201 & $40 \%(34 \%, 47 \%) *$ \\
\hline 2 & Never had pap exam. & 43 & $84 \%(73 \%, 95 \%) *$ \\
\hline \multicolumn{4}{|c|}{ South Asian $(N=125)$} \\
\hline 1 & Has no health insurance. & $<10$ & $100 \%$ \\
\hline 2 & Has health insurance. Age $\geq 50$. & 53 & $21 \%(10 \%, 32 \%)$ \\
\hline 3 & Has health insurance. Age $<50$. Unemployed. & 20 & $65 \%(44 \%, 86 \%)^{*}$ \\
\hline 4 & Has health insurance. Age < 50. Employed. U.S. citizen. & 32 & $25 \%(10 \%, 40 \%)$ \\
\hline 5 & Has health insurance. Age < 50. Employed. Non U.S. citizen. & 15 & $60 \%(35 \%, 85 \%)^{*}$ \\
\hline \multicolumn{4}{|c|}{ Vietnamese $(N=226)$} \\
\hline 1 & Ever had pap exam. & 180 & $20 \%(14 \%, 26 \%)$ \\
\hline 2 & Never had pap exam. & 46 & $72 \%(59 \%, 85 \%)^{*}$ \\
\hline
\end{tabular}

*does not meet HP 2010 goal 


\section{Discussion}

Despite overall improvements in mammography screening nationwide, there remain disparities in screening among certain population subgroups, including Asians. This study, an analysis of data from a large, populationbased sample of Asian women in California, takes advantage of a novel statistical method with the ability to identify discrete subgroups of women who do not appear to be following screening guidelines. This method identified two important characteristics defining Asian women in this category: 1) those who have never had a pap exam to screen for cervical cancer, and 2) those who do not use hormone therapy, have osteoporosis, or have not had a hysterectomy. Previous studies have not reported any of these characteristics as predictors of mammography use. We also found that among women meeting either 1) or 2) above, those with no usual source of health care, were also likely to not follow mammography screening guidelines. Having no usual source of health care has been reported previously as a determinant of mammography use $[12,14,24]$. Our findings suggest that Asian women who do not follow mammography screening recommendations also do not follow guidelines for other cancer screening tests and may not have good access to health care, so effective programs to improve screening in these groups should focus not just on mammography but on all cancer screening tests. Women's health issues may be a key discriminator of regular recipients of mammograms, as this finding suggests that women may be referred or reminded more often by their physician to obtain mammograms and/or are more diligent about their health in general. In addition, providers treating these conditions may be more likely to be specialists in women's health, and thus more diligent in referring patients to mammography screening. Furthermore, the relationship between using hormone replacement therapy, and possibly treatment for osteoporosis, and breast cancer etiology may result in increased vigilance and surveillance for cancer $[42,46-49]$ thereby prompting providers to recommend routine mammograms for these women. However, it does not appear that routine use of the health care system for other health issues is related to mammography use, as having arthritis, asthma, diabetes, or high blood pressure was not associated with having a mammogram in the past two years in our analysis. Additional focus should be placed on primary care physicians to promote age-appropriate cancer screening. Health plans should also have systems enabling health personnel to issue reminders or even schedule screening appointments for patients who are being seen for other health issues.

The heterogeneity of Asians as a single group [50] is supported by our subgroup-specific findings, and should be emphasized when developing programs targeting specific Asian ethnic communities. Specifically, Chinese non-citi- zens were at highest risk for not having a mammogram within the past two years. Citizenship status has not previously been shown to be a determinant of mammography use; it may be related to predictors of mammography use found in other studies such as poorer language proficiency, decreased acculturation, and foreign birth [1719,22,24-27,29-31], although language, education, and birthplace did not emerge as being particularly salient predictors in our study. Being a U.S. citizen may also be associated with having health insurance benefits, familiarity with and trust in Western biomedicine and facility in navigating the American health care system. Among Filipinas who have had pap or colorectal cancer screening, having health insurance was the next strongest delineator of adherence to screening guidelines among Filipinas; this characteristic has been noted elsewhere [27]. Other than pap screening, Korean women without women's health issues and either public or no health insurance had the lowest mammography use, and this finding is supported by previous studies showing lack of insurance as a barrier to mammography screening [51]. In South Asians, we found that despite having health insurance and being employed, non-citizens under age 50 were at high risk of not having a mammogram. Among Vietnamese women, pap screening was an important predictor, as was single marital status, a finding reported previously $[17,18,24,26]$. Future studies should focus on elucidating explanations of these predictors, and outreach efforts to target these subgroups, particularly among South Asian and Vietnamese women, for whom considerably less research has been conducted.

This study has a number of strengths. We used RP, an emerging but currently under-used, powerful statistical technique to identify meaningful subgroups of Asian women at high-risk for not following mammogram screening recommendations. $\mathrm{RP}$ is suitable for identifying high-risk subgroups as it creates combinations of variables that best describe mammography use. Because of the exploratory nature of this technique, we found several factors associated with mammography use that have not previously been shown in the literature. However, RP also confirmed other factors, such as health insurance and marital status, which have previously been shown to be associated with mammography screening among Asians, suggesting that RP can be reliably applied to this research question. This technique was applied recently to a prospective study of 1229 African-American and White women in Connecticut to similarly identify subgroups of women who did not adhere to mammogram screening guidelines [33]. Our study, however, is the first, to our knowledge to apply RP to a large population-based behavioral risk factor survey to address this issue among Asian American women. The large sample size in this study allowed for analysis of most of the Asian ethnic subgroups 
surveyed in CHIS. CHIS 2001 was conducted in several languages allowing less acculturated and/or more recently immigrated Asians to be included in the analysis. The survey was also reviewed by experts to assure cultural compatibility and comprehensibility to target population groups. The demographic distributions of CHIS respondents were comparable to those from other surveys, suggesting that the survey was representative [38].

Our study also had several weaknesses. Because it was a secondary data analysis, we were limited in the variables we could examine. In particular, our dependent variable is a limited assessment of mammography use in the past two years. Because the information on screening and predictors were all based on self-report, differential misclassification may occur if misclassification in self-reporting of the predictor variables was associated with misclassification in reporting of mammography. Future studies designed specifically to address this question using RP might also incorporate cultural factors, such as knowledge and perceptions about preventive medical care, cancer screening, and breast cancer risk [26,51,52]; and modesty and embarrassment issues associated with mammography $[27,52,53]$. The response rates for CHIS 2001 were relatively low, yet these response rates are similar to the rates found in other population health surveys, such as the 2002 BRFSS [38]. Since CHIS is a telephone-based survey, selection biases such as non-coverage of households without telephones and households who "screen" telephone calls, as well as higher response rates among individuals of higher socioeconomic status, inherent to telephone surveys may exist.

\section{Conclusion}

In addition to documented socioeconomic and financial barriers, our findings suggest institutional, cultural, and linguistic barriers for Asian-American women meeting mammography screening recommendations. Specifically, our results suggest that there are three major categories of Asian American women who require additional targeted efforts to improve their screening behaviors, and that different approaches are required for each group. The first group of women includes those who have health insurance and access their health care but do not see providers who specialize in women's health issues. This group may benefit from receiving reminders through their primary care providers or health care plan. The second group includes those who have health insurance and a usual source of care but who do not routinely access health care. These women tend to be more likely to be recent immigrants or non-citizens and have limited English facility. Public health and health-care based interventions should continue to focus on culturally- and linguistically-appropriate strategies for targeting these women. The third group includes those who do not have health insurance and/or a usual source of care. Outreach for this group could be effectively achieved through promoting screening through public insurance carriers, state-funded screening programs, and community-based interventions. Together with these methods, our data should be helpful in providing direction to those designing and implementing future interventions of benefit to the community of Asian women and in increasing rates of cancer screening in this group.

\section{Competing interests}

The author(s) declare that they have no competing interests.

\section{Authors' contributions}

SLG conceived of the study, conducted aspects of the data analysis, and drafted the manuscript. ST participated in the design of the study, conducted the data analysis, and drafted the manuscript. THMK and CAC participated in the interpretation of data and drafted the manuscript.

\section{Acknowledgements}

The authors thank Laura McClure, Sarah Aroner, and the CHIS staff, particularly Lee Habte and Wei Yen, for their assistance with this manuscript. The funding for this analysis was supported under contracts NOI-CN65107 and N0I-PC-35I36 with the National Cancer Institute, National Institutes of Health, and with support of the California Cancer Registry, a project of the Cancer Surveillance Section, California Department of Health Services, under subcontracts 100089 I and N02-PC-I5I05 with the Public Health Institute, and by the Centers for Disease Control and Prevention's National Program of Cancer Registries under agreement U55/ CCR921930-02 awarded to the Public Health Institute. The content of this publication does not necessarily reflect the views or policies of the US Department of Health and Human Services or the California Department of Health Services, nor does mention of trade names, commercial products, or organizations imply endorsement by the US Government or state of California.

\section{References}

I. U.S. Census Bureau, Current Population Reports: Profile of the Foreign-Born Population in the United States, 2000. 200I.

2. U.S. Census Bureau, Current Population Reports: The ForeignBorn Population in the United States. 2000.

3. The Asian Population: 2000. In Census 2000 Brief US Census Bureau; 2002:7.

4. Census Bureau Projects Tripling of Hispanic and Asian Populations in 50 Years; Non-Hispanic Whites May Drop To Half of Total Population. In US Census Bureau News Washington D.C. , US Department of Commerce; 2004

5. Asian \& Pacific Islander Center for Census Information and Services: Our Ten Years of Growth: a Demographic Analysis on Asian and Pacific Islander Americans. Edited by: Consortium APID. San Francisco, CA ; 1992

6. Asian American Federation Census Information Center: New National Demographic Profile Shows Increasing Diversity of Asian Americans. New York ; 2001.

7. Asian Pacific American Legal Center of Southern California, Asian Law Caucus, National Asian Pacific American Legal Consortium: The Diverse Face of Asians and Pacific Islanders in California. Asian \& Pacific Islander Demographic Profile. Los Angeles, CA ; 2005.

8. Cockburn M, Deapen D: Cancer Incidence and Mortality in California: Trends by Race/Ethnicity, I988-200 I. Los Angeles, 
California , Los Angeles Cancer Surveillance Program, University of Southern California; 2004.

9. Cresswell S, Gomez SL, Clarke CA, Chang ET, Keegan THM, McClure L, Glaser SL, West DW: Cancer Incidence and Mortality in the Greater Bay Area, 1988-2004. Edited by: Center NCC. Fremont, CA ; 2007.

10. Humphrey LL, Helfand M, Chan BK, Woolf SH: Breast cancer screening: a summary of the evidence for the U.S. Preventive Services Task Force. Ann Intern Med 2002, I37(5 Part I):347-360.

II. National Health Interview Survey Public Use Data File 2000. In National Center for Health Statistics Centers for Disease Control and Prevention; 2002.

12. Kagawa-Singer M Pourat, N.: Asian American and Pacific Islander Breast and Cervical Carcinoma Screening Rates and Healthy People 2000 Objectives. Cancer 2000, 89(3):696-705.

13. Ponce NA, Babey SH, Etzioni DA, Spencer BA, Chawla N: Cancer Screening in California: Findings from the $200 \mathrm{I}$ California Health Interview Survey. Los Angeles, UCLA Center for Health Policy Research; 2003.

14. Kim K, Yu E, Chen E, Kim JK, Brintnall R: Breast Cancer Screening Knowledge and Practices Among Korean American Women. Asian Am Pac Isl J Health 1998, 6(2):263-275.

15. Ko CM, Sadler GR, Ryujin L, Dong A: Filipina American women's breast cancer knowledge, attitudes, and screening behaviors. Biomed Central Public Health 2003, 3(I):27.

16. Maxwell AE, Bastani R, Warda U: Mammography Utilization and Related Attitudes Among Korean-American Women. Women \& Health 1998, 27(3):89-107.

17. McPhee SJ, Stewart S, Brock KC, Bird JA, Jenkins CN, Pham GQ: Factors associated with breast and cervical cancer screening practices among Vietnamese American women. Cancer Detect Prev 1997, 2I (6):5I0-52I.

18. McPhee SJ, Bird JA, Davis T, Ha NT, Jenkins CN, Le B: Barriers to breast and cervical cancer screening among VietnameseAmerican women. American Journal of Preventive Medicine 1997 13(3):205-2/3.

19. Sadler GR, Wang K, Wang M, Ko CM: Chinese women: behaviors and attitudes toward breast cancer education and screening. Women's health Issues 2000, I (1):20-26.

20. Sadler GR, Dong HS, Ko CM, Luu TT, Nguyen HP: Vietnamese American women: Breast cancer knowledge, attitudes, and screening adherence. American Journal of Health Promotion 200I, I5(4):2I|-2|4.

21. Sadler GR, Takahashi M, Nguyen T: Japanese American women: Behaviors and attitudes toward breast cancer education and screening. Health Care for Women International 2003, 24(I): 18-26.

22. Tang TS, Solomon LJ, McCracken LM: Cultural barriers to mammography, clinical breast exam, and breast self-exam among Chinese-American women $\mathbf{6 0}$ and older. Preventive Medicine 2000, 5:575-583.

23. Wismer BA, Moskowitz JM, Chen AM, Kang SH, Novotny TE, Min K, Lew R, Tager IB: Mammography and clinical breast examination among Korean American women in two California counties. Preventive Medicine 1998, 27(I): I44-I5I.

24. $Y_{i} J K$, Reyes-Gibby CC: Breast cancer screening practices among low-income Vietnamese women. International Quarterly of Community Health Education 2002, 2 I ( I):4 I-49.

25. Yu MY, Hong OS, Seetoo AD: Uncovering factors contributing to under-utilization of breast cancer screening by Chinese and Korean women living in the United States. Ethn Dis 2003 , I3(2):213-219.

26. Ho V, Yamal JM, Atkinson EN, Basen-Engquist K, Tortolero-Luna G Follen M: Predictors of breast and cervical screening in Vietnamese women in Harris County, Houston, Texas. Cancer Nurs 2005, 28(2): I I 9-29; quiz I 30-I.

27. Maxwell AE, Bastani R, Warda U: Breast Cancer Screening and Related Attitudes Among Filipino American Women. Cancer Epidemiol Biomarkers Prev 1997, 6(9):719-726.

28. Wu TY, Yu MY: Reliability and Validity of the Mammography Screening Beliefs Questionnaire Among Chinese American Women. Cancer Nursing 2003, 26(2): | $31-142$.

29. Lee M, Lee F, Stewart S: Pathways to early breast and cervical detection for Chinese American women. Health Education Quarterly 1996, 23:S76-S88.
30. Yu ES, Kim KK, Chen EH, Brintnall RA: Breast and cervical cancer screening among Chinese American women. Cancer Practice 200I, 9(2):8I-9I.

31. Maxwell AE, Bastani R, Warda U: Demographic Predictors of Cancer Screening Among Filipino and Korean Immigrants in the United States. American Journal of Preventive Medicine 2000, I8(I):62-68.

32. Lee M, Lee F, Stewart S, Mcphee S: Cancer Screening Practices Among Primary Care Physicians Serving Chinese Americans in San Francisco. The Western Journal of Medicine 1999, I70(3): I 148-155.

33. Calvocoressi L, Stolar M, Kasl SV, Claus EB, Jones BA: Applying recursive partitioning to a prospective study of factors associated with adherence to mammography screening guidelines. Am J Epidemiol 2005, 162(1 2): | 215-1224

34. Babey SH, Ponce NA, Etzioni DA, Spencer BA, Brown ER, Chawla N: Cancer screening in California: racial and ethnic disparities persist. UCLA Center for Health Policy Research Policy Brief 2003.

35. Ponce NA, Gatchell M, Brown ER: Cancer screening rates among Asian ethnic subgroups. UCLA Center for Health Policy Research Policy Brief 2003.

36. Lin SS, Clarke CA, Prehn AW, Glaser SL, West DW, O'Malley CD: Survival differences among Asian subpopulations in the United States after prostate, colorectal, breast, and cervical carcinomas. Cancer 2002, 94(4): I |75- I I 82.

37. California Health Interview Survey: About CHIS. [http:// www.chis.ucla.edu/about.html].

38. California Health Interview Survey: The CHIS 200I Sample: Response Rate and Representativeness. In California Health Interview Survey: Technical Paper \#I Los Angeles, UCLA Center for Health Policy Research; 2003: I-6.

39. California Health Interview Survey: CHIS 200I Methodology Series: Report 4 - Response Rates. Los Angeles, UCLA Center for Health Policy Research; 2002.

40. American Cancer Society: ACS Cancer Detection Guidelines. [http://www.cancer.org/docroot/PED/ contenPED 2 3X ACS Cancer Detection Guidelines 36.asp?sitea rea $=$ PED]

41. Collins R, Winkleby MA: African American women and men at high and low risk for hypertension: a signal detectiona analysis of NHANES III, 1988-1994. Preventive Medicine 2002, 35:303-312.

42. Nelson L, Bloch D, Longstretch W, Shi H: Recursive Partitioning for the Identification of Disease Risk Subgroups: A CaseControl Study of Subarachnoid Hemorrhage. Journal of Clinical Epidemiology 1998, 5 I (3): 199-209.

43. U.S. Department of Health and Human Services: Healthy People 20I0. 2nd ed. With Understanding and Improving Health and Objectives for Improving Health. 2 vols. Edited by: Office USGP. Washington, DC; 2000 .

44. Lewis RJ: An Introduction to Classification and Regression Tree (CART) Analysis: San Francisco, CA. ; 2000.

45. Atkinson EJ, Therneau TM: An introduction to recursive partitioning using the RPART routines: Mayo Foundation. 2000.

46. Brieman L, Friedman JH, Olshen RA, Stone CJ: Classification and Regression Trees. Belmont, CA, Wadsworth; 1984

47. Colditz GA, Hankinson SE, Hunter DJ, et al.: The use of estsrogens and progestins and the risk of breast cancer in postmenopausal women. New England Journal of Medicine 1995, 332:I589-1593.

48. Joffe MM, Byrne C, Colditz GA: Postmenopausal hormone use, screening, and breast cancer: characterization and control of a bias. Epidemiology 200I, I 2:429-438.

49. Schairer C, Byrne C, Heyl P, et al:: Menopausal estrogen and and estrogen-progestin replacement therapy and risk of breast cancer (United States). Cancer Causes Control I 994, 5(49 I-500):

50. Chen JY, Diamant AL, Kagawa-Singer M, Pourat N, Wold C: Disaggregating data on Asian and Pacific Islander women to assess cancer screening. American Journal of Preventive Medicine 2004, 27(2): 139-145.

5I. Juon HS, Kim M, Shankar S, Han W: Predictors of adherence to screening mammography among Korean American women. Prev Med 2004, 39(3):474-48।.

52. Moy B, Park ER, Feibelmann S, Chiang S, Weissman JS: Barriers to repeat mammography: cultural perspectives of AfricanAmerican, Asian, and Hispanic women. Psychooncology 2006:623-634 
53. Lee M: Breast and Cervical Cancer: Early Detection in Chinese American Women. Asian Am Pac Isl J Health 1998, 6(2):35I-357.

\section{Pre-publication history}

The pre-publication history for this paper can be accessed here:

http://www.biomedcentral.com/1471-2407/7/201/pre

pub

Publish with Biomed Central and every scientist can read your work free of charge

"BioMed Central will be the most significant development for disseminating the results of biomedical research in our lifetime. " Sir Paul Nurse, Cancer Research UK

Your research papers will be:

- available free of charge to the entire biomedical community

- peer reviewed and published immediately upon acceptance

- cited in PubMed and archived on PubMed Central

- yours - you keep the copyright
BioMedcentral 